\title{
Injury to Peritoneum without mention of Open Wound into Cavity
}

National Cancer Institute

\section{Source}

National Cancer Institute. Injury to Peritoneum without mention of Open Wound into

Cavity. NCI Thesaurus. Code C35248.

Trauma to the peritoneum without indication of associated damage to the skin and other internal and external tissues. 